\title{
Modeling of large railway polygons
}

\author{
Yelena Timukhina ${ }^{1, *}$, Petr Kozlov ${ }^{2}$, Vitaly Kolokolnikov ${ }^{1}$, and Nikolay Tushin ${ }^{1}$ \\ ${ }^{1}$ Ural State University of Railway Transport, 620034 Yekaterinburg, Russia \\ ${ }^{2}$ STRATEG Scientific-Production Holding, 101000 Moscow, Russia
}

\begin{abstract}
When large junctions of railway polygons are studied, detailed modeling is subject to some limitations. Therefore, it is necessary to develop appropriate tools. This paper presents an aggregate (macromodeling) technique for necks and yards of railway stations. Results of calculations based on aggregate models are highly consistent with results of detailed modeling, which confirms the applicability of this modeling method to railway polygons. The proposed principles were implemented on the basis of the IMETRA simulation system. The resulting polygon model makes it possible to determine the total throughput of a polygon and to identify bottlenecks that slow down car traffic.
\end{abstract}

\section{Introduction}

At present, simulation modeling is the most adequate and accurate method for designing railway stations. However, stations operate in close relationship with adjacent stations, lines and polygons. Therefore, it is required to model not only separate stations, but also junctions, sections and entire polygons. It is extremely difficult to use detailed modeling for this purpose. It is necessary to develop a new modeling method that will reduce the amount of input information and a data array for calculations, without significant detriment to the adequacy of the model.

Simulation modeling of stations was first proposed by professor V. A. Persianov in the 1960s [1]. Despite the scarce computer resources available at that time, V. A. Persianov, together with professor N. S. Uskov, came up with some interesting findings. Since then, much progress has been made in this area [2-7].

Simulation modeling of stations and polygons differs in terms of objectives and nature [8]. A station model is usually aimed at assessing a specific development project. Therefore, it should be as detailed as possible and provide a sufficient set of indicators to determine not only the overall throughput and capacity, but also the role of each structural element. At present, the ISTRA system is the most developed imitation system in this area [9]. However, it is difficult to extend this approach to modeling of polygons. We need about 600-700 thousand strings to fully describe the model of a large station with all operations, implementation options, devices involved in each option and their operating parameters. A polygon may include several hundred stations, including dozens of large ones, thereby producing a huge, difficult-to-process array.

* Corresponding author: ENTimuhina@usurt.ru 
The objective of the study is a different one. In a new problem statement, it is necessary to determine the overall throughput of the polygon, while aggregating its bottlenecks. If these are stations that slow down the car traffic, it is enough to know involved necks and yards, without identifying specific switches. However, at the second stage, when it is necessary to reorganize a particular station, detailed modeling should be used.

\section{Principles of macromodeling}

\subsection{Neck macromodeling technique}

The aim of macromodeling is to take into account only throughput of a neck in the model without further detailing. In a functional approach, the key parameter of the neck is the number of possible parallel movements. These movements are numbered. Each movement is managed by a certain group of switches. It is kind of a virtual service channel. Train receiving and dispatching operations or shunting movements are served by some virtual channels. Thus, throughput of necks is taken into account, even though in aggregate form.

Unlike a separate switch, the channel has an explicit meaningful purpose - it enables one additional parallel movement [10]. It is the number of parallel movements that will determine possible maneuverability, and, hence, potential throughput of the neck (Fig. 1).

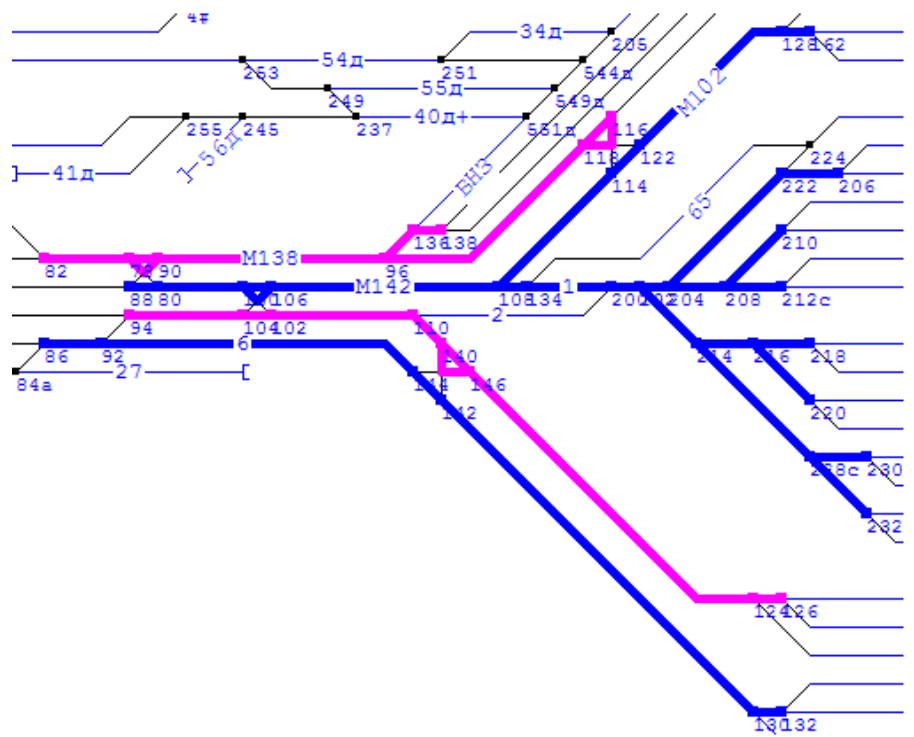

Fig. 1. Structural channels in the neck of the Karymskaya station.

However, the real throughput implemented for selected process conditions may differ from the potential one. The smaller the average number of involved channels per operation is, the closer they will be to each other and, hence, the better the technology will fit the structure.

To verify the validity of the proposed approach, it is necessary to compare operating parameters of necks on the basis of detailed and aggregate models. In this case, the number of delays in throats is the key factor as well. Comparative calculations for several stations show a good coincidence between the results (Fig. 2). Thus, the proposed principles can also be applied to the construction of polygon models. 


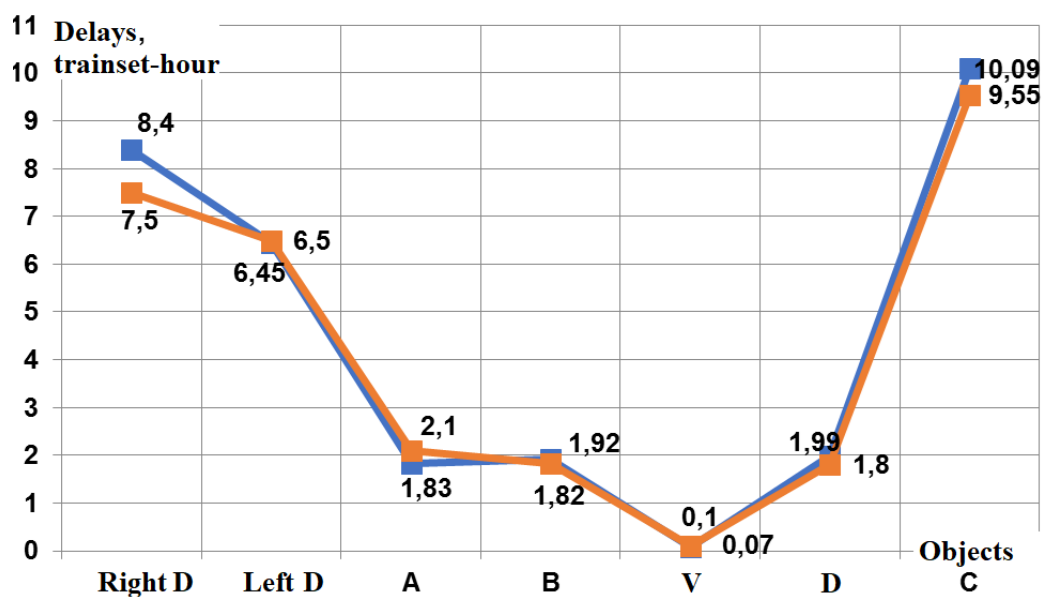

Fig. 2. Delays in throats: blue - in the micromodel, red - in the macromodel.

\subsection{Macromodeling of yards}

In our case, we use the ultimate functional capacity of the yard (i. e. the capacity at which its functionality is still maintained), rather than the total physical capacity of tracks, as an input parameter for modeling yards. Naturally, a difference between the functional capacity and the physical capacity will vary depending on type of a yard. In this case, coincidence of delays due to yards and the time of stay of trains or cars in yards are used as criteria.

The comparative calculations based on the detailed and aggregate models of various stations show that the results almost coincide with each other.

\subsection{Outputs}

Based on the proposed principles of macromodeling, the IMETRA imitation system was developed [11]. Using this system, we constructed a model of the Kuzbass-Ust-Luga polygon (283 stations). Based on the outputs, it is possible to assess the performance of the entire polygon and to study the influence of individual factors.

The estimated period was ten or more days. The outputs include a car passing pattern of the polygon (Table 1) and an actual train schedule (Fig. 3). In addition, operations of locomotives with each train are visualized. 
Table 1. Delays of Trains by Type.

\begin{tabular}{|c|c|c|c|c|}
\hline subprocess & graphically & per day & number & per operation \\
\hline $71 \mathrm{HEY}$ & & $1191: 51$ & 7091,6 & $0: 10$ \\
\hline 71 ЧЕТ & & $1124: 51$ & 7405,6 & 0:09 \\
\hline $66 \mathrm{HEY}$ & & $914: 57$ & 5068,7 & $0: 10$ \\
\hline 66 ЧЕТ & & $315: 49$ & 1756,6 & $0: 10$ \\
\hline 58 ЧЕТ & & 297:00 & 1382,1 & $0: 12$ \\
\hline 100 ЧЕТ & & $250: 40$ & 1587,1 & 0:09 \\
\hline $58 \mathrm{HEY}$ & & $235: 18$ & 837,4 & $0: 16$ \\
\hline $100 \mathrm{HEY}$ & & $57: 21$ & 266,9 & $0: 12$ \\
\hline 85 HEY & & $51: 48$ & 275 & $0: 11$ \\
\hline лкм & & $13: 20$ & 44,9 & $0: 17$ \\
\hline приг ЧЕТ & & $0: 18$ & 32 & $0: 01$ \\
\hline Пасс HEЧ & & $0: 15$ & 25 & $0: 01$ \\
\hline приг НЕЧ & & $0: 04$ & 20 & $0: 01$ \\
\hline Пасс ЧЕТ & & $0: 00$ & 0 & $0: 00$ \\
\hline
\end{tabular}

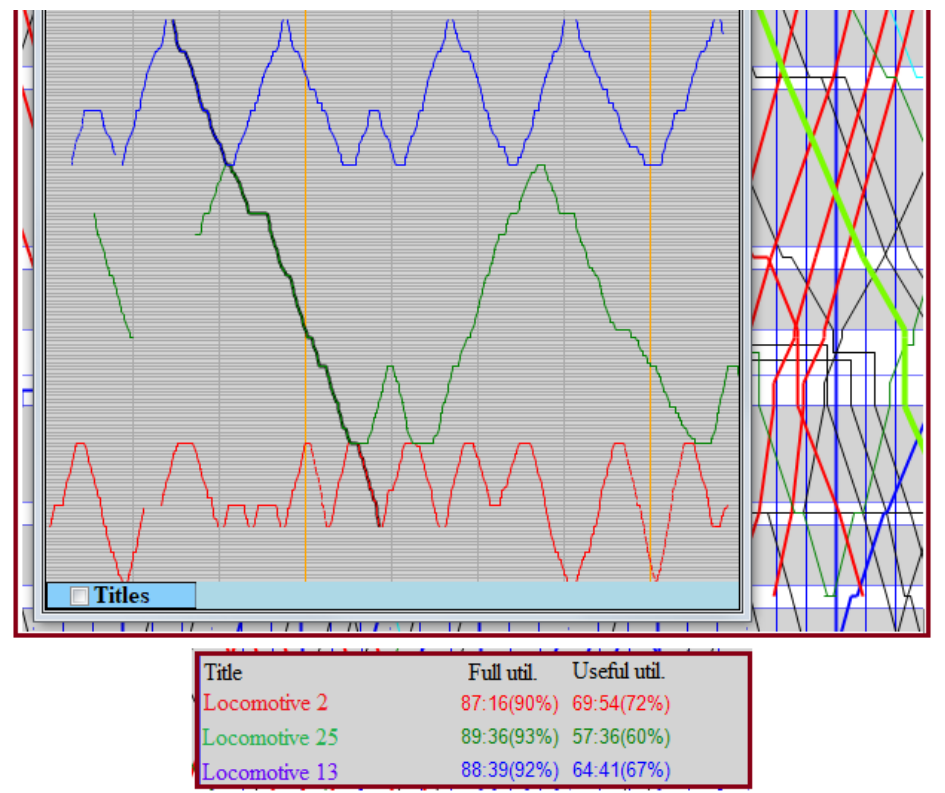

Fig. 3. An executed traffic schedule with parameters of locomotive utilization.

For the purpose of the analysis, the progression of train traffic should be estimated in more detail by calculating the following parameters:

- average speed of car traffic on each railway line;

- running and sectional speeds in all sections, etc. 
The layout of the polygon below shows stations and sections that cause train delays (Fig. 4).

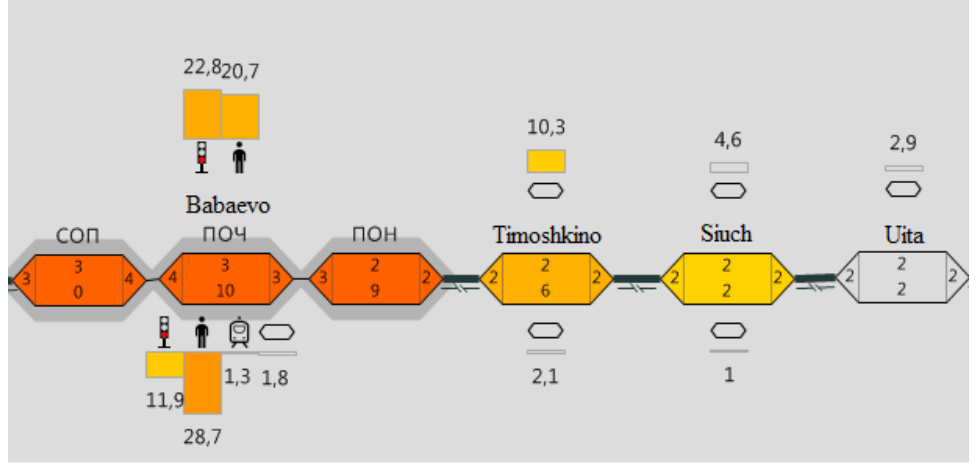

Fig. 4. Delays of trains at stations.

Additional delays (except for delays at passing points) are shown for wayside stations. The traffic graph shows that intermediate stations are subject to irregular conditions (Fig. 5).

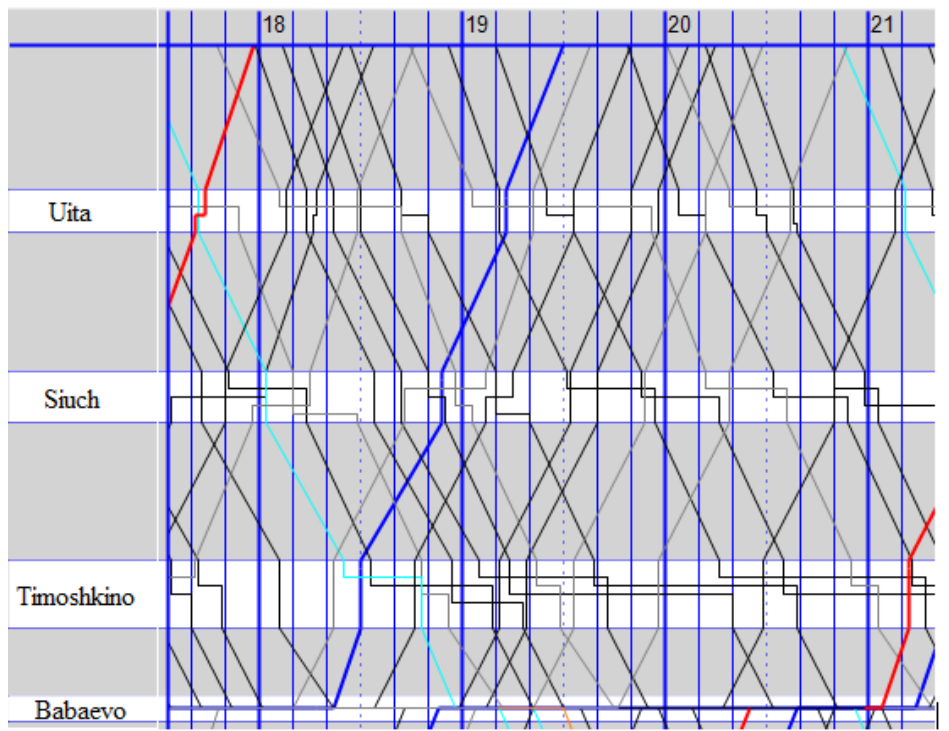

Fig. 5. Delays of trains at wayside stations.

Thus, optimal train schedules constructed by the Elbrus system (developed by the Scientific Research Institute of Railway Transport) usually cannot be implemented in real conditions. The model clearly demonstrates why particular trains and sets of cars are idle at technical stations (average values per train: at the top in one direction, at the bottom in another direction) (Fig. 6). 


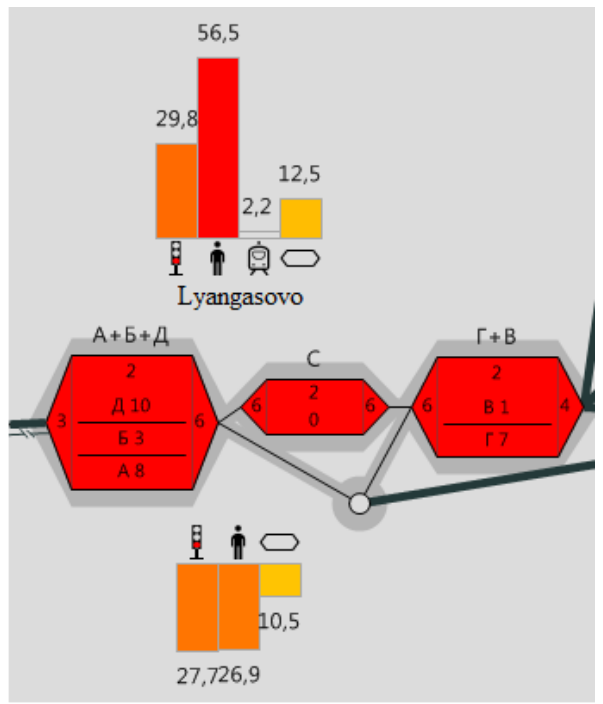

Fig. 6. Delays of trains at technical stations.

Delays are distributed as follows:

- through fault of yard crews - $56.5 \mathrm{~min}$ and $26.9 \mathrm{~min}$;

- absence of a locomotive - 2.2 minutes;

- impossibility to start a ready-to-depart train $-29.8 \mathrm{~min}$ and $27.7 \mathrm{~min}$;

- including due to lack of tracks at the next technical station - $12.5 \mathrm{~min}$ and $10.5 \mathrm{~min}$.

Delays due to locomotives vary from section to section, while their effective utilization does not exceed $50 \%$ of the total utilization time (Fig. 7).

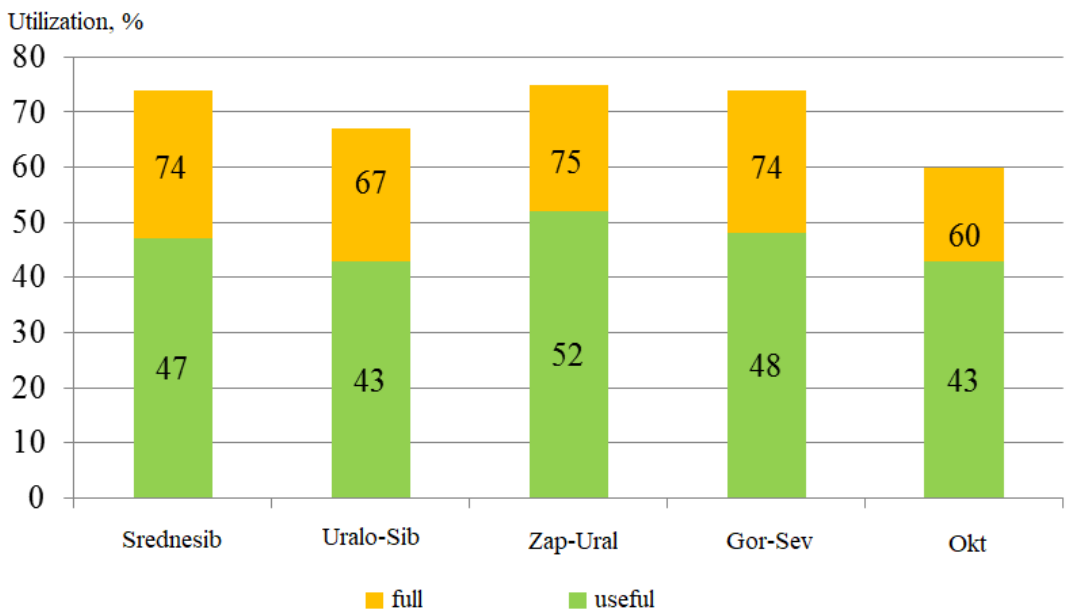

Fig. 7. Full and effective utilization of locomotives.

\section{Conclusion}

The railway network is struggling to cope with increasing train traffic. It needs to be intensively developed and, therefore, requires multi-billion dollar investments. Simulation modeling is the most appropriate tool for evaluating their effectiveness. The 
macromodeling method developed by the authors makes it possible to assess the operational efficiency and development of railroad polygons by imitation [12]. In the future, it is necessary to build a single polygon model from eastern to western borders of Russia and assess possible options for its structural and technological development.

\section{References}

1. V.A. Persianov, K.Yu. Skalov, N.S. Uskov, Modelirovanie transportnyh sistem [Modeling of transport systems] (Transport, Moscow, 1972). (in Russian)

2. B. Shmidt, Iskusstvo modelirovanija i imitacii: Vvedenie v imitacionnuju sistemu Simplex 3 [Modeling and Simulation: An Introduction to the Simplex 3 Simulation System] (St. Petersburg, 2003). (in Russian)

3. N. Adamko, V. Klima, P. Marton, International Journal of Civil Engineering, 8, 58-67 (2010).

4. G. Medeossi, Capacity and reliability on railway networks: a simulative approach/ (Anno accademico, Triest, 2009).

5. A.E. Aleksandrov, A.V. Shipulin, Transport of the Urals, 4, 67-71 (2011). (in Russian)

6. I.M. Kokurin, V.S.Timchenko, Bulletin of the Emperor Alexander I St. Petersburg State Transport University, 1, 15-22 (2013). (in Russian)

7. V.S. Timchenko, K.E. Kovalev, D.I. Khomich, Imitacionnoe modelirovanie na zheleznodorozhnom transporte [Simulation modeling in railway transport] (LAMBERT Academic Publishing, Saarbruecken, 2017). (in Russian)

8. A.E. Aleksandrov, Doctoral thesis, Ural State University of Railway Transport, Yekaterinburg, 2008. (in Russian)

9. V.Yu. Permikin, Thesis of Candidate of Sciences, Ural State University of Railway Transport, Yekaterinburg, 1999. (in Russian)

10. P.A. Kozlov, V.S. Kolokolnikov, Transport of the Urals, 3, 3-7 (2017). (in Russian)

11. P.A. Kozlov, I.O. Naboychenko, V.Yu. Permikin, Zheleznodorozhnyj transport [Railway transport], 3, 26-29 (2016). (in Russian)

12. P.A. Kozlov, V.S. Kolokolnikov, O.V. Osokin, Zheleznodorozhnyj transport [Railway transport], 6, 12-16 (2018). (in Russian) 